Article

\title{
Production of a Thermostable Chitosanase from Shrimp Heads via Paenibacillus mucilaginosus TKU032 Conversion and its Application in the Preparation of Bioactive Chitosan Oligosaccharides
}

\author{
Chien Thang Doan ${ }^{1,2}\left(\mathbb{D}\right.$, Thi Ngoc Tran ${ }^{1,2}$, Van Bon Nguyen ${ }^{2}(0)$ Anh Dzung Nguyen ${ }^{3}(\mathbb{C}$ and \\ San-Lang Wang 1,4,*(D) \\ 1 Department of Chemistry, Tamkang University, New Taipei City 25137, Taiwan; \\ doanthng@gmail.com (C.T.D.); tranngoctnu@gmail.com (T.N.T.) \\ 2 Department of Science and Technology, Tay Nguyen University, Buon Ma Thuot 630000, Vietnam; \\ bondhtn@gmail.com \\ 3 Institute of Biotechnology and Environment, Tay Nguyen University, Buon Ma Thuot 630000, Vietnam; \\ nadzungtaynguyenuni@yahoo.com.vn \\ 4 Life Science Development Center, Tamkang University, New Taipei City 25137, Taiwan \\ * Correspondence: sabulo@mail.tku.edu.tw; Tel.: +886-2-2621-5656; Fax: +886-2-2620-9924
}

Received: 19 March 2019; Accepted: 9 April 2019; Published: 10 April 2019

check for updates

\begin{abstract}
Chitosanase has attracted great attention due to its potential applications in medicine, agriculture, and nutraceuticals. In this study, P. mucilaginosus TKU032, a bacterial strain isolated from Taiwanese soil, exhibited the highest chitosanase activity $(0.53 \mathrm{U} / \mathrm{mL})$ on medium containing shrimp heads as the sole carbon and nitrogen $(\mathrm{C} / \mathrm{N})$ source. Using sodium dodecyl sulfate-polyacrylamide gel electrophoresis (SDS-PAGE) analysis, a chitosanase isolated from P. mucilaginosus TKU032 cultured on shrimp head medium was determined at approximately $59 \mathrm{kDa}$. The characterized chitosanase showed interesting properties with optimal temperature and thermal stability up to $70{ }^{\circ} \mathrm{C}$. Three chitosan oligosaccharide (COS) fractions were isolated from hydrolyzed colloidal chitosan that was catalyzed by TKU032 chitosanase. Of these, fraction I showed the highest $\alpha$-glucosidase inhibitor (aGI) activity $(65.86 \%$ at $20 \mathrm{mg} / \mathrm{mL})$; its inhibitory mechanism followed the mixed noncompetitive inhibition model. Fractions II and III exhibited strong 2,2-diphenyl1-picrylhydrazyl (DPPH) radical scavenging activity $(79.00 \%$ at $12 \mathrm{mg} / \mathrm{mL}$ and $73.29 \%$ at $16 \mathrm{mg} / \mathrm{mL}$, respectively). In summary, the COS fractions obtained by hydrolyzing colloidal chitosan with TKU032 chitosanase may have potential use in medical or nutraceutical fields due to their aGI and antioxidant activities.
\end{abstract}

Keywords: chitin; chitosan; Paenibacillus; chitosanase; chitosan oligomers; $\alpha$-glucosidase inhibitor; antioxidant

\section{Introduction}

Chitosan is a polymer composed of $\beta-1,4$ linked D-glucosamine with varying amounts (under $50 \%$ ) of $N$-acetyl-D-glucosamine [1]. Chitosan is of interest to many researchers as it exhibits various biological activities and has many biotechnological uses [2-4]. Unfortunately, chitosan has poor solubility at neutral $\mathrm{pH}$, potentially limiting its application. Chitosan oligosaccharides (COS) are products obtained from hydrolyzed chitosan with an average MW of less than 3900 Da and degrees of polymerization (DP) under 20 [5]. Unlike chitosan, COS possess great solubility in water. Furthermore, COS also demonstrate antidiabetic [6,7], prebiotic [8,9], antioxidant [5,8], anti-inflammatory [5,10], anticancer [10], antitumor [11], and antibacterial biological activities [12,13]. The enzymatic method 
was recently reported as an efficient and environmentally friendly process for producing bioactive $\operatorname{COS}[5,8,9,14-16]$. However, the high cost of enzyme production limits its application on a larger scale. As such, an inexpensive and efficient protocol for producing chitinolytic enzymes and converting chitosan into bioactive COS is needed.

Chitosanase (EC 3.2.1.132) is a group of enzymes which hydrolyzes chitosan [17]. It is a useful tool for depolymerizing chitosan into oligosaccharides with various biological activities and degrees of DP [5,9]. Important sources for chitosanase production have primarily been found in bacteria, including Paenibacillus [9,18], Bacillus [5,19-23], Serratia [24], and Streptomyces [25]. Until now, the common C/N sources for chitosanase production via bacteria were chitin and chitosan. Commercialized chitin and chitosan products are mostly prepared from fish processing by-products, such as shrimp shells, crab shells, or squid pens, using chemical methods like strong alkaline and acid treatments to remove proteins and mineral salts. To reduce costs, shrimp shells, shrimp heads, crab shells and squid pens have been used as the sole $\mathrm{C} / \mathrm{N}$ sources for enzyme production via microbial conversion [18-22,26-31].

Recently, several strains of Paenibacillus showed excellent ability in producing $\alpha$-glucosidase inhibitors [32-36], proteases [18], chitosanase [9,18], and exopolysaccharides [37,38] when marine chitinous materials were used as the sole $\mathrm{C} / \mathrm{N}$ source. In the previous report, $P$. mucilaginosus TKU032, a bacterial strain isolated from Taiwanese soil, produced exopolysaccharides with high antioxidant activity from a medium containing squid pens [37]. Moreover, the culture supernatant also showed chitinolytic, proteolytic and aGI activities [18]. This suggests that P. mucilaginosus TKU032 has the potential to produce various biological activities using low-cost chitinous materials. However, an investigation into TKU032's enzyme production was not fully explored.

In this study, chitosanase production of P. mucilaginosus TKU032 was tested using four kinds of marine chitinous materials: squid pens powder (SPP), shrimp heads powder (SHP), demineralized shrimp shells powder (deSSP), and demineralized crab shells powder (deCSP) to determine the most suitable $\mathrm{C} / \mathrm{N}$ source for bioconversion. The isolation and characterization of P. mucilaginosus TKU032 chitosanase was performed. Furthermore, the COS obtained by hydrolyzing colloidal chitosan with P. mucilaginosus TKU032 chitosanase were fractionated and characterized. The aGI and antioxidant activities of the COS fractions were also estimated and compared to commercial compounds.

\section{Results and Discussion}

\subsection{Screening of Chitinous Materials as Sole C/N Source for Chitosanase Production}

To explore chitosanase production by P. mucilaginosus TKU032, four chitinous materials from fish processing (SPP, SHP, deCSP, and deSSP) were used as the sole $\mathrm{C} / \mathrm{N}$ sources during incubation. As shown in Figure 1, TKU032 chitosanase was found to exhibit the highest activity at day 2 of the cultivation on all types of chitinous material sources, in which the maximum enzyme activity was expressed with SHP $(0.53 \mathrm{U} / \mathrm{mL})$ higher than SPP $(0.42 \mathrm{U} / \mathrm{mL}, p$-value 0.0384$)$, deCSP $(0.25 \mathrm{U} / \mathrm{mL}$, $p$-value 0.0028$)$, and deSSP $(0.18 \mathrm{U} / \mathrm{mL}, p$-value 0.0005$)$, respectively. The reason might be related to the difference in protein/chitin/mineral salts ratio of each chitinous material, in which SHP contents had higher amounts of protein and mineral salts but lower amount of chitin than those of the other materials $[36,39]$. This result was also unlike previous reports, which suggested that chitosanase from Paenibacillus strains often show the highest activity on medium containing SPP $[9,18]$.

In the search to find a suitable and cost effective source for producing bioactive compounds via microorganism conversion, shrimp heads, a by-product from shrimp processing, were suggested as potential material as they have been reported as the best sole $\mathrm{C} / \mathrm{N}$ source for producing chitosanase (B. cereus TKU027) [14], aGI (Staphylococcus sp. TKU043) [29], nattokinase (B. subtilis TKU007) [30], and protease (B. cereus TKU022, B. licheniformis TKU004) [22,31]. Since TKU032 showed the highest chitosanase activity on medium containing SHP, it was chosen as the sole $\mathrm{C} / \mathrm{N}$ source. 

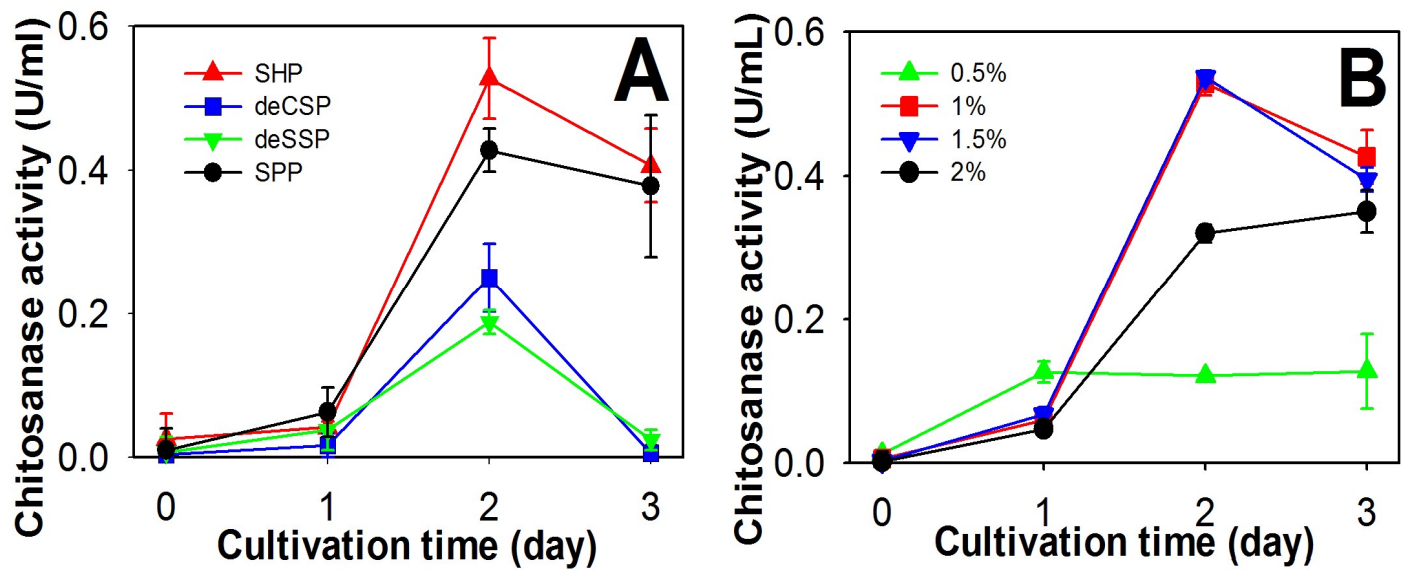

Figure 1. Production of chitosanase by P. mulaginosus TKU032; (A) using different chitin-containing materials as the $\mathrm{C} / \mathrm{N}$ source; (B) using different concentrations of SHP.

Further experimentation determined the optimal SHP concentration for chitosanase conversion by $P$. mulaginosus TKU032. As shown in Figure 1B, the highest chitosanase activity was found at $1 \% \operatorname{SHP}(0.53 \mathrm{U} / \mathrm{mL})$ and $1.5 \% \operatorname{SHP}(0.54 \mathrm{U} / \mathrm{mL})$. Since there was no significant difference in maximum chitosanase activity ( $p$-value 0.5037 ) and less material loss, $1 \%$ SHP was chosen for subsequent experiments.

\subsection{Comparison of Chitosanase Production from SHP Using Different Bacteria}

Chitinase/chitosanase production by chitinolytic Paenibacillus and Bacillus strains on SPP and deCSP-containing media were introduced in our previous report [18]. In this study, the potency of SHP in chitinase/chitosanase production via microorganism conversion was also investigated. The results in Table 1 show that all tested species of Paenibacillus and Bacillus exhibited chitinase and chitosanase activities. The highest chitosanase and chitinase activities were found in P. mucilaginosus TKU032 $(0.58 \mathrm{U} / \mathrm{mL}$ and $0.37 \mathrm{U} / \mathrm{mL})$ and P. macerans TKU029 $(0.59 \mathrm{U} / \mathrm{mL}$ and $0.28 \mathrm{U} / \mathrm{mL})$ with no significant difference in their activities ( 0.88 and 0.1563 of $p$-value, respectively); the results were better than those of Paenibacillus sp. TKU037 $(0.05 \mathrm{U} / \mathrm{mL}$ and $0.06 \mathrm{U} / \mathrm{mL})$, Paenibacillus sp. TKU042 $(0.12 \mathrm{U} / \mathrm{mL}$ and $0.12 \mathrm{U} / \mathrm{mL})$, B. subtillis TKU007 $(0.05 \mathrm{U} / \mathrm{mL}$ and $0.11 \mathrm{U} / \mathrm{mL})$, and B. licheniformis TKU004 $(0.01 \mathrm{U} / \mathrm{mL}$ and $0.04 \mathrm{U} / \mathrm{mL})$ with a $p$-value range from 0.0004 to 0.0025 . By expressing the higher chitinolytic activity on chitosan $(0.58 \mathrm{U} / \mathrm{mL})$ than on chitin $(0.37 \mathrm{U} / \mathrm{mL}), P$. mucilaginosus TKU032 could be considered as a chitosanase-producing bacterium. Similar to the previous study, none of the tested Paenibacillus species, including P. mucilaginosus TKU032, showed exochitinase activity [18]. Taken together, this result confirmed that SHP was the most suitable $\mathrm{C} / \mathrm{N}$ source for chitosanase production via P. mucilaginosus TKU032 conversion.

Table 1. Comparison of chitosanase, chitinase, and exochitinase production by different Paenibacillus and Bacillus strains.

\begin{tabular}{cccc}
\hline Bacterial Strain & $\begin{array}{c}\text { Chitosanase Activity } \\
\mathbf{( U / m L )}\end{array}$ & $\begin{array}{c}\text { Chitinase Activity } \\
\text { (U/mL) }\end{array}$ & $\begin{array}{c}\text { Exochitinase Activity } \\
\text { (U/mL) }\end{array}$ \\
\hline P. mucilaginosus TKU032 & $0.58 \pm 0.10$ & $0.37 \pm 0.04$ & - \\
P. macerans TKU029 & $0.59 \pm 0.04$ & $0.28 \pm 0.08$ & - \\
Paenibacillus sp. TKU037 & $0.05 \pm 0.02$ & $0.06 \pm 0.05$ & - \\
Paenibacillus sp. TKU042 & $0.12 \pm 0.04$ & $0.12 \pm 0.05$ & - \\
Bacillus licheniformis TKU004 & $0.01 \pm 0.01$ & $0.04 \pm 0.01$ & $10.21 \pm 0.89$ \\
B. subtillis TKU007 & $0.05 \pm 0.02$ & $0.11 \pm 0.01$ & - \\
\hline
\end{tabular}

Bacterial strains were cultured in $100 \mathrm{~mL}$ of liquid medium in an Erlenmeyer flask (250 mL) containing $1 \% \mathrm{SHP}$, $0.1 \% \mathrm{~K}_{2} \mathrm{HPO}_{4}$ and $0.05 \% \mathrm{MgSO}_{4} \cdot 7 \mathrm{H}_{2} \mathrm{O}$ in a shaking incubator for $2 \mathrm{~d}$ at $37^{\circ} \mathrm{C}$. 


\subsection{Purification and Characterization of Chitosanase}

In order to characterize TKU032 chitosanase, a series of steps was used to purify the enzyme, including $\left(\mathrm{NH}_{4}\right)_{2} \mathrm{SO}_{4}$ precipitation, Macro-prep High $\mathrm{S}$ ion exchange chromatography and KW802.5 gel filtration. The chitosanase was eluted by $20 \mathrm{mM}$ Tris- $\mathrm{HCl}$ buffer ( $\mathrm{pH}$ 7) with a linear gradient of 0-1 M NaCl on a Macro-prep High S column. As shown in Figure 2, there was only one peak of chitosanase activity, located at the washing stage of the ion-exchange chromatography separation. This result indicated that $\mathrm{pI}$ of TKU032 chitosanase might be $\geq 7$. The peak fractions (fraction numbers 5-15) showing chitosanase activity were collected. After Macro-Prep High S chromatography, 15.98 $\mathrm{mg}$ of protein was obtained with an increase in the specific activity from $0.7 \mathrm{U} / \mathrm{mg}$ to $4.25 \mathrm{U} / \mathrm{mg}$ and a slight reduction in the activity yield from $31.69 \%$ to $24.06 \%$. The purification was then confirmed by HPLC gel filtration using the KW802.5 column. Similar to the ion-exchange chromatography, only one peak of chitosanase activity was found by the HPLC analysis (data not showed). After purification, one chitosanase was obtained; its profile is summarized in Table 2. In other reports, only one chitinase/chitosanase was isolated from the culture medium of Paenibacillus species [1, $9,18,40-48]$. The specific activity and recovery yield of the purified chitosanase were $5.13 \mathrm{U} / \mathrm{mg}$ and $10.94 \%$, respectively. By using SDS-PAGE analysis, the molecular weight (MW) of the TKU032 chitosanase was determined as approximately $59 \mathrm{kDa}$ (Figure 3), which fell within the MW's range (35-85 kDa) of chitinase/chitosanase from most Paenibacillus strains $[1,9,18,40-48]$, with an exception from Paenibacillus sp. FPU-7 chitinase (150 kDa) [49].
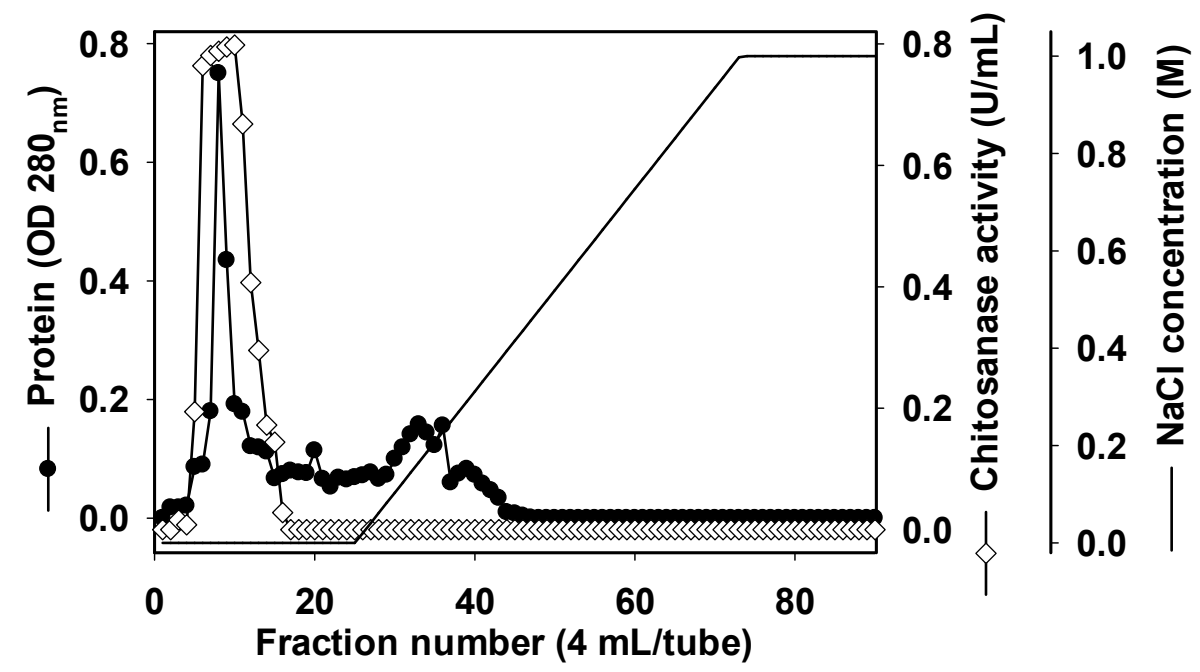

Figure 2. A typical elution profile of chitosanase on Macro-prep High S column.

Table 2. Purification of chitosanase from P. mucilaginosus TKU032.

\begin{tabular}{cccccc}
\hline Step & $\begin{array}{c}\text { Total Protein } \\
\text { (mg) }\end{array}$ & $\begin{array}{c}\text { Total } \\
\text { Activity (U) }\end{array}$ & $\begin{array}{c}\text { Specific Activity } \\
\text { (U/mg) }\end{array}$ & Recovery (\%) & $\begin{array}{c}\text { Purification } \\
\text { (Fold) }\end{array}$ \\
\hline Cultural supernatant & 1499.13 & 282.28 & 0.19 & 100.00 & 1.00 \\
$\left(\mathrm{NH}_{4}\right)_{2} \mathrm{SO}_{4}$ precipitation & 126.97 & 89.44 & 0.70 & 31.69 & 3.74 \\
Macro-Prep High S & 15.98 & 67.92 & 4.25 & 24.06 & 22.57 \\
KW-802.5 & 5.13 & 30.89 & 6.03 & 10.94 & 32.01 \\
\hline
\end{tabular}

P. mucilaginosus TKU032 was cultured in $100 \mathrm{~mL}$ of liquid medium in an Erlenmeyer flask $(250 \mathrm{~mL})$ containing $1 \%$ SHP, $0.1 \% \mathrm{~K}_{2} \mathrm{HPO}_{4}$ and $0.05 \% \mathrm{MgSO}_{4} \cdot 7 \mathrm{H}_{2} \mathrm{O}$ in a shaking incubator for $2 \mathrm{~d}$ at $37^{\circ} \mathrm{C}$. 


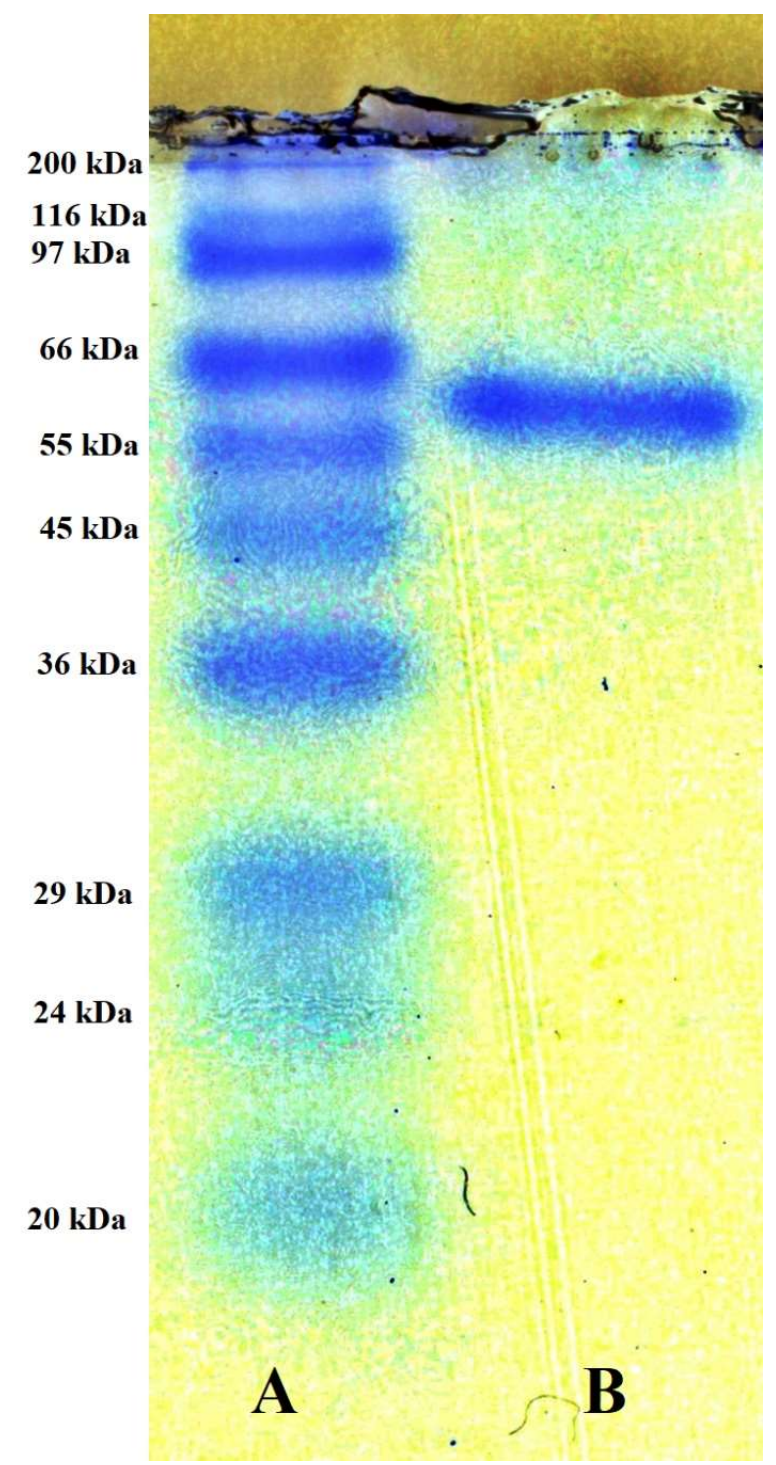

Figure 3. SDS-PAGE analysis of the chitosanase produced by TKU032. A: protein markers; B: Purified chitosanase.

\subsection{Effects of $\mathrm{pH}$ and Temperature on Activity and Stability of Chitosanase}

The effect of $\mathrm{pH}$ on P. mucilaginosus TKU032 chitosanase is shown in Figure 4A. The optimum $\mathrm{pH}$ for the enzyme was 6.0. This result is consistent with most research, which showed chitinase/chitosanase from Paenibacillus species expressing the highest activity in acidic conditions [1, 41,45-47], with the exceptions of P. macerans TKU029 [9], P. pasadenensis NCIM5434 [43] and P. elgii HOA73 [42]. P. mucilaginusus TKU032 was stable over a broad $\mathrm{pH}$ range (Figure $4 \mathrm{~A}$ ), with over $80 \%$ of activity retained from $\mathrm{pH} 4$ to 8 . Once the $\mathrm{pH}$ dropped below 4 , activity disappeared completely, whereas $50 \%$ of activity was retained at $\mathrm{pH}$ 9. Several chitinase/chitosanase from Paenibacillus showed the same broad $\mathrm{pH}$ stability as P. mucilaginosus TKU032 $[9,46,48,50]$. 

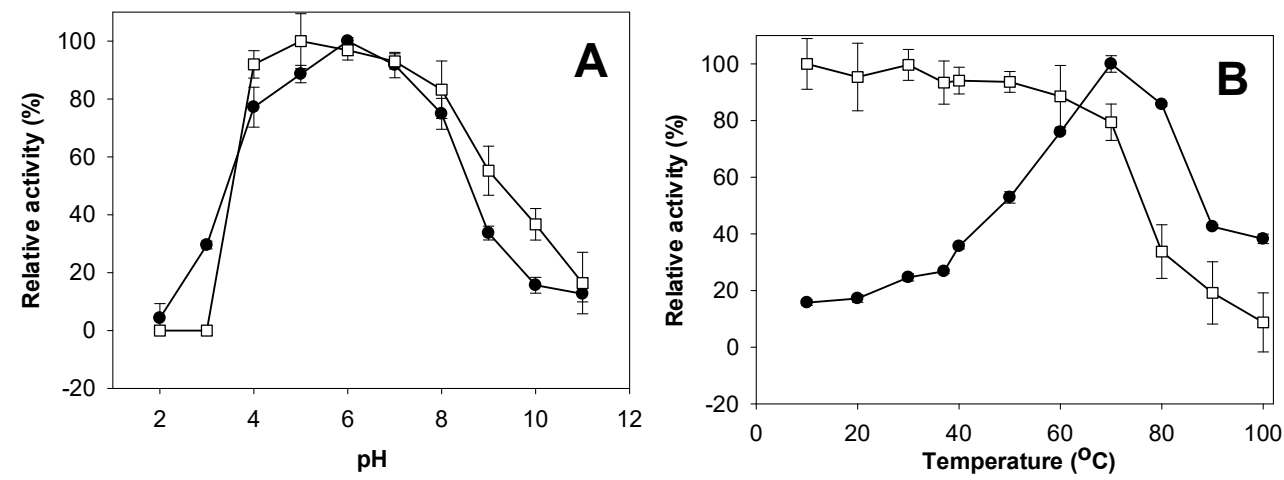

Figure 4. Effect of $\mathrm{pH}(\mathbf{A})$ and temperature (B) on activity $(\bullet)$ and stability ( $\square$ ) of TKU032 chitosanase.

The effect of temperature on the activity and stability of $P$. mucilaginosus TKU032 chitosanase were studied herein (Figure 4B). The optimal temperature was $70^{\circ} \mathrm{C}$, but even at $80^{\circ} \mathrm{C}$, it still showed more than $80 \%$ activity. P. mucilaginosus TKU032 chitosanase demonstrated thermal stability up to $70{ }^{\circ} \mathrm{C}$, with over $80 \%$ of activity retained. This suggests that both the optimal temperature and thermal stability of P. mucilaginosus TKU032 chitosanase were higher than most chitinase/chitosanase from other Paenibacillus species [9,41-47]; only a chitosanase from Paenibacillus sp. 1794 showed similar results [1]. Due to its higher thermal stability, P. mucilaginosus TKU032 chitosanase may have potential use in industrial applications.

\subsection{Effect of Metal Ions on Activity of Chitosanase}

The effects of known divalent metals and enzyme inhibitors on the activity of TKU032 chitosanase were examined; the results are summarized in Table 3. All chemicals reduced the activity of TKU032 chitosanase, a result markedly different from other reports, which showed that the addition of some metal ions, $\mathrm{Na}^{+}$and $\mathrm{Fe}^{2+}$ for instance, could enhance the activity of chitosanases from Paenibacillus $[9,50]$.

Table 3. Effect of metal ions on the activity of chitosanase

\begin{tabular}{cc}
\hline Metal Ion & Relative Activity (\%) \\
\hline Control & $100.00 \pm 6.39$ \\
$\mathrm{Cu}^{2+}$ & $74.37 \pm 3.95$ \\
$\mathrm{Zn}^{2+}$ & $76.78 \pm 3.25$ \\
$\mathrm{Mg}^{2+}$ & $84.39 \pm 4.51$ \\
$\mathrm{Na}^{+}$ & $91.71 \pm 5.21$ \\
$\mathrm{Ba}^{2+}$ & $62.14 \pm 12.29$ \\
$\mathrm{Ca}^{2+}$ & $77.07 \pm 5.68$ \\
$\mathrm{Fe}^{2+}$ & $65.13 \pm 6.77$ \\
EDTA & $84.39 \pm 7.53$ \\
\hline
\end{tabular}

\subsection{Substrate Specificity of Chitosanase}

The activity of the purified P. mucilaginosus TKU032 chitosanase on various substrates is shown in Figure 5. Chitosanase activity was expressed in the descending order of colloidal chitosan $>$ cellulose $>$ chitosan $>$ colloidal chitin $>$ water-soluble chitosan $>\beta$-chitin $>\alpha$-chitin. No activity was shown on dextran, starch, or $p$-nitrophenyl- $N$-acetyl- $\beta$-D-glucosaminide ( $p$ NPG). These results suggest that the physical form of the substrate had a strong effect on the rate of hydrolysis. Unlike P. macerans TKU029 chitosanase, where the most suitable substrate was water-soluble chitosan [9], P. mucilaginosus TKU032 chitosanase demonstrated excellent activity on colloidal chitosan (338.74\%), followed by chitosan powder (185.38\%). It also showed good activity on chitin substrates, expressing $113.24 \%$, $67.19 \%$, and $27.67 \%$ on colloidal chitin, $\beta$-chitin, and $\alpha$-chitin, respectively, as well as on cellulose 
(196.84\%). These results indicate that P. mucilaginosus TKU032 chitosanase could express good activity on various types of substrates, including cellulose, chitin, and chitosan. Since $p$ NPG is a specific substrate of exochitinase, it was logical that P. mucilaginosus TKU032 chitosanase would not show any exochitinase activity.

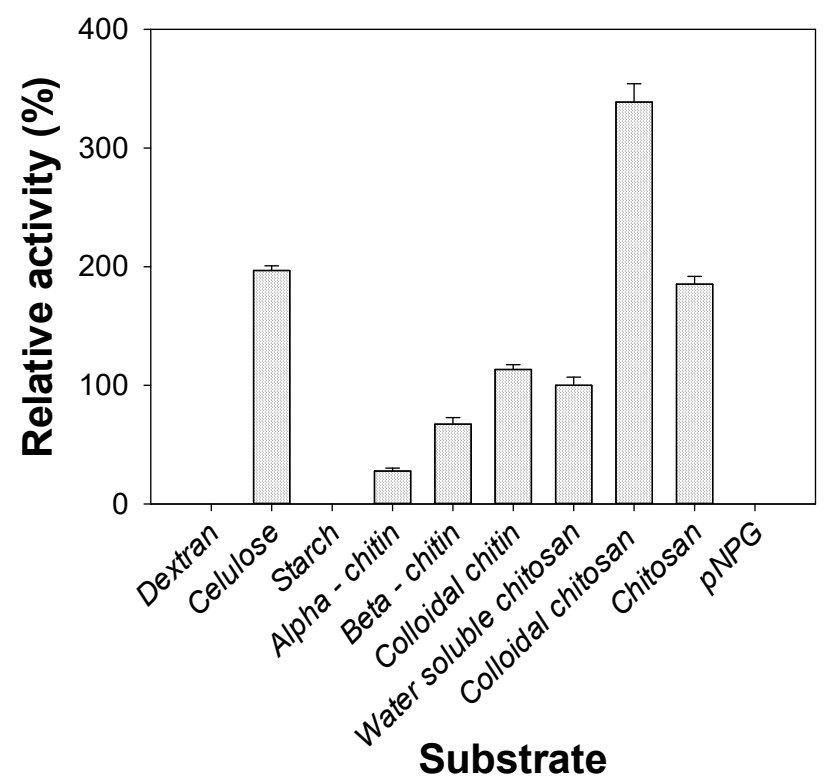

Figure 5. Substrate specificity of P. mucilaginosus TKU032 chitosanase.

\subsection{COS Production}

Since P. mucilaginosus TKU032 chitosanase expressed the best activity on colloidal chitosan, this substrate was used to produce COS using the enzyme hydrolysis method. After the reaction finished, a series of steps were used to separate COS from the hydrolyzed solution, including $\mathrm{pH}$ neutralization, centrifugation, and dialysis by a 10,000 Da membrane. The obtained COS was then fractionated by $\mathrm{MeOH} 90 \%$ precipitation and gel filtration on a Toyopearl HW-40f column. As shown in Figure 6, 3 COS fractions were collected from the hydrolyzed chitosan solution. The molecular weights of the obtained fractions were determined by HPLC analysis using a KS-802 column (Figure 7). The molecular weights of fractions I, II, and III were approximately 1600-6500 Da, 424-6500 Da, and 221-424 Da, respectively. Fraction I only contained COS with higher MW, while fraction II was a mixture of COS with high and low MW, and fraction III included COS with the lowest MW. Compared to the reference peaks, fraction III mainly contained COS with DP from 1 to 2.

\subsection{Evaluation of Antioxidant and aGI Activities of COS Fractions}

Free radicals negatively affect living organisms, resulting in DNA mutation, lipid and protein damage, cancer, and cardiovascular or neurodegenerative diseases [51]. The harmful actions of free radicals could be reduced or prevented by antioxidant compounds. In the current study, the DPPH radical scavenging ability was assayed to explore the antioxidant activity of the three obtained COS fractions. As shown in Figure 8A, within a concentration range of $1-20 \mathrm{mg} / \mathrm{mL}$, only fractions II and III showed DPPH radical scavenging activity with a dose-dependent increase. The maximum antioxidant activity of fraction II was $79.00 \%$ at a concentration of $12 \mathrm{mg} / \mathrm{mL}$, while fraction III was $73.29 \%$ at $16 \mathrm{mg} / \mathrm{mL}$. This suggests that fraction II is the strongest antioxidant among the three fractions. It is well known that COS is a potential candidate for antioxidant activity; however, its antioxidant ability was strongly affected by its MW [5,8]. The obtained results indicated that COS with lower MW could possess higher antioxidant activity. Moreover, this study also showed that low MW COS with $\mathrm{DP}>2$ expressed higher DPPH radical scavenging activity than COS with DP $\leq 2$. Compared to 
ascorbic acid, a commercial antioxidant compound, fraction II expressed weaker activity. The two compounds generated maximum activity at concentrations of $4 \mathrm{mg} / \mathrm{mL}$ and $12 \mathrm{mg} / \mathrm{mL}$, respectively. However, as there was no significant difference ( $p$-value 0.404$)$ between the maximum activity of ascorbic acid $(82.29 \%)$ and fraction II $(79.00 \%)$, fraction II may have comparable antioxidant activity. As such, COS fraction II could be an acceptable antioxidant compound for use in the medical or food industries.

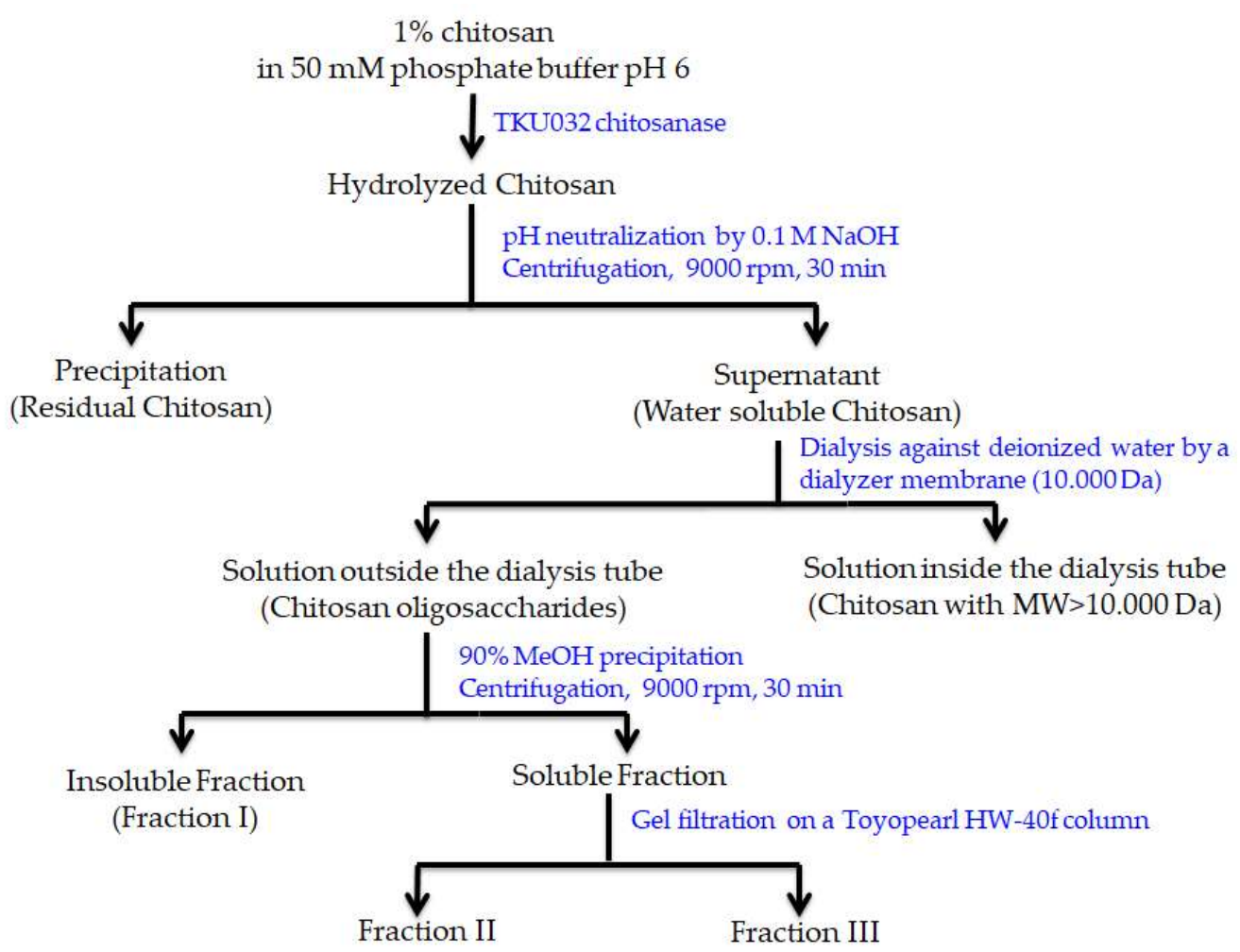

Figure 6. Flow chart for the isolation of COS produced by hydrolyzing chitosan with TKU032 chitosanase
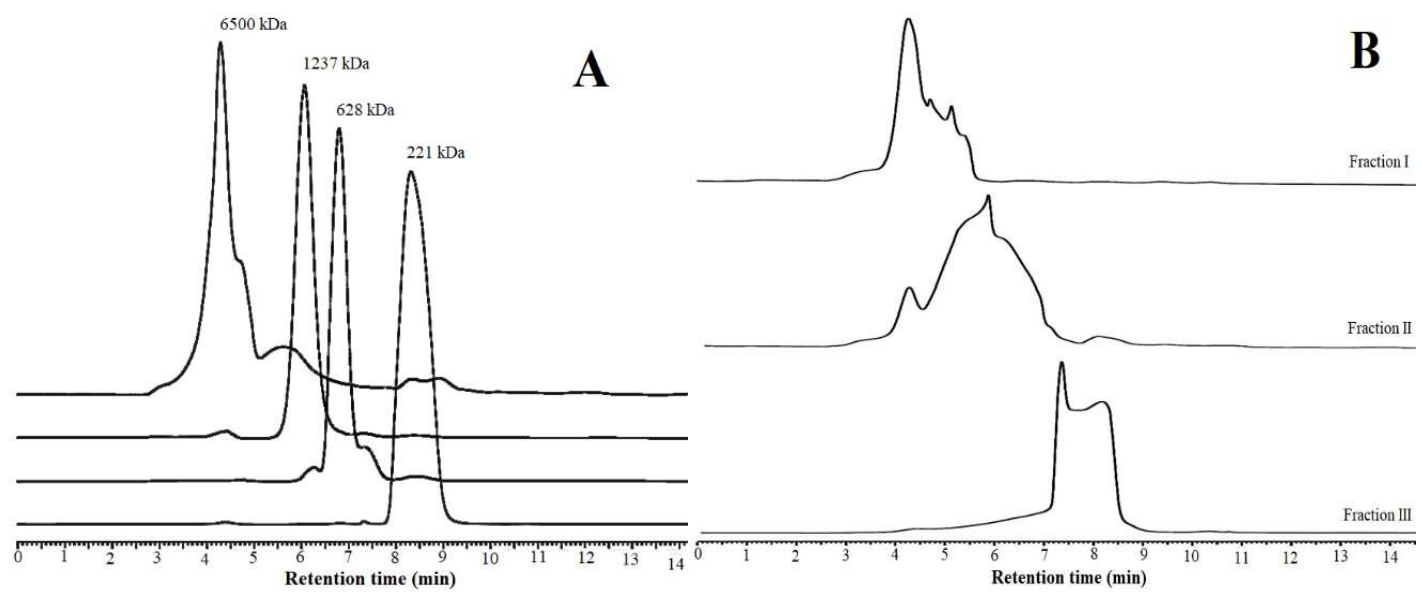

Figure 7. HPLC profiles of chitosan oligosaccharide fractions: (A) references; (B) chitosan oligosaccharide fractions 

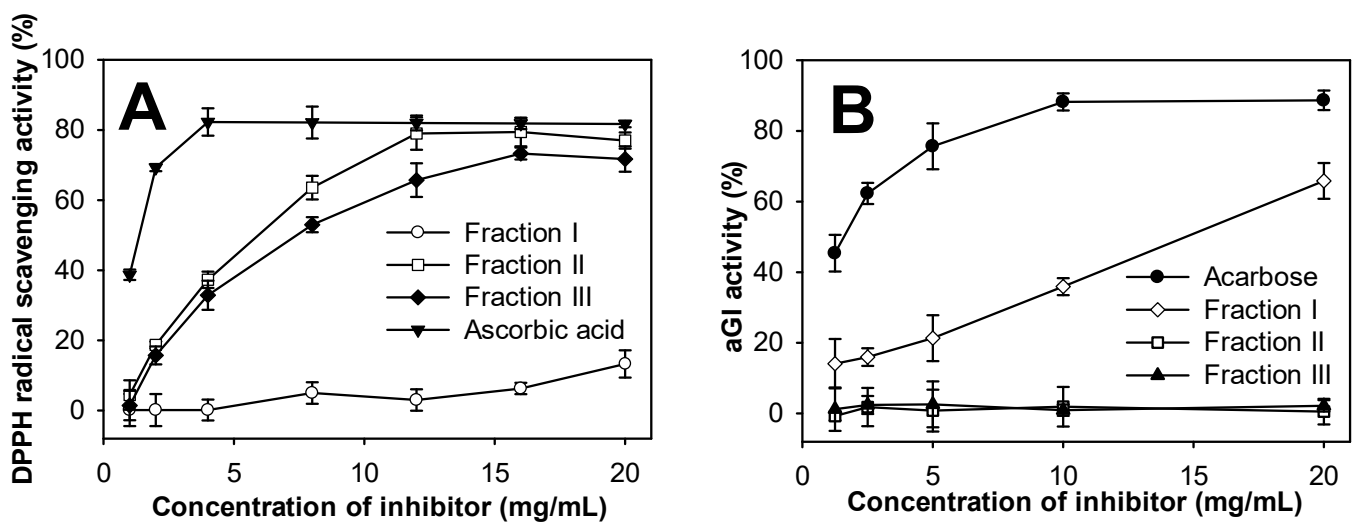

Figure 8. (A) antioxidant and (B) aGI activities of COS fractions.

As $\alpha$-glucosidase inhibitors are an important therapy for type 2 diabetes, the COS fractions were also investigated for $\alpha$-glucosidase inhibitor activity. As shown in Figure 8B, only fraction I expressed dose-dependent aGI activity within a range of 1-20 mg/mL. At $20 \mathrm{mg} / \mathrm{mL}$, fraction I exhibited $65.86 \%$ inhibitory activity on yeast $\alpha$-glucosidase, which was weaker than acarbose $(88.21 \%$ at $10 \mathrm{mg} / \mathrm{mL})$ with 0.0005 of $p$-value. Only COS with higher MW showed aGI activity, unlike the results of Jo et al. (2013) who found similar aGI activity in rat $\alpha$-glucosidase from 3 different molecular weight COS fractions [6]. For further investigation, the inhibition model of fraction I on yeast $\alpha$-glucosidase was analyzed using a Lineweaver-Burk plot. Figure 9 shows that when the concentration of COS fraction I increased from 0 to $20 \mathrm{mg} / \mathrm{mL}, 1 / \mathrm{V}_{\mathrm{M}}$ increased but $-1 / \mathrm{K}_{\mathrm{M}}$ varied. This suggests that the aGI activity of COS fraction I follows the mixed noncompetitive inhibition model. Although chitosan and COS have been widely studied for treating diabetes [52], there have been few reports on their inhibition of $\alpha$-glucosidase, a key enzyme in the digestive system that hydrolyzes dietary carbohydrates to increase blood glucose concentration. As such, this result could prove a novel contribution to aGI research.

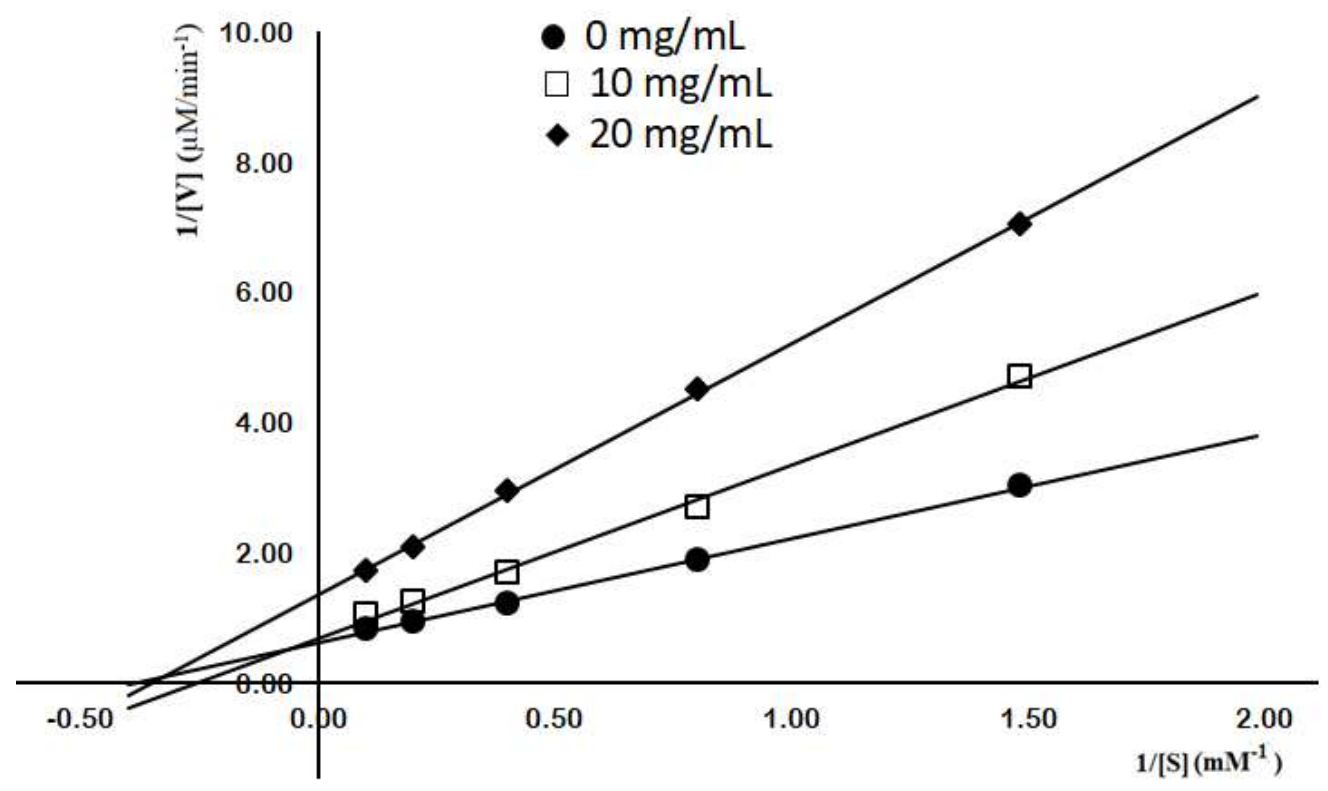

Figure 9. Lineweaver-Burk plot analysis of aGI activity by COS fraction I.

\section{Materials and Methods}

\subsection{Materials}

Shrimp shells, squid pens, and crab shells were purchased from Shin-Ma Frozen Food Co. (I-Lan, Taiwan). Shrimp heads was bought from Fwu-Sow Industry (Taichun, Taiwan). Shrimp shells 
and crab shells were demineralized by acid treatment [8]. All bacterial strains were provided by the Microorganisms and Biochemistry Laboratory, Department of Chemistry, Tamkang University, New Taipei, Taiwan. Chitosan, DPPH, yeast $\alpha$-glucosidase and 3,5-dinitrosalicylic acid (DNS) reagents were all bought from Sigma-Aldrich Corp. (Singapore). Macro-Prep High S was bought from Bio-Rad (Hercules, CA, USA). All other reagents used were the highest grade available.

\subsection{Measurement of Chitosanase Activity}

The chitosanase activity assay was modified from previously described methods [18]. The substrate solution was prepared by adding water-soluble chitosan into $20 \mathrm{mM}$ Tris- $\mathrm{HCl}$ buffer at $\mathrm{pH} 7$ to reach a final concentration of $1 \%(\mathrm{w} / \mathrm{v})$. The hydrolysis reaction of chitosan was performed with $100 \mu \mathrm{L}$ of the sample and $100 \mu 1$ of substrate, and maintained at $37^{\circ} \mathrm{C}$ in an incubator for $30 \mathrm{~min}$. The DNS method was used to detect the amount of reducing sugar produced, with D-glucosamine used as the reference. The definition of a unit of chitosanase activity was the amount of enzyme catalyzed to produce $1 \mu \mathrm{mol}$ of reducing sugar in one min.

\subsection{Screening of Chitinous Materials as Sole C/N Source for Chitosanase Activity}

Four fishery by-products: deCSP, SPP, SHP, and deSSP, were added to $100 \mathrm{~mL}$ of basal medium $\left(0.1 \% \mathrm{~K}_{2} \mathrm{HPO}_{4}\right.$ and $\left.0.05 \% \mathrm{MgSO} \cdot 7 \mathrm{H}_{2} \mathrm{O}\right)$ in $250 \mathrm{~mL}$ Erlenmeyer flasks at similar concentrations (1\%) [9]. Fermentation was performed with $1 \%$ of seed culture at $37^{\circ} \mathrm{C}$ and a shaking speed of $150 \mathrm{rpm}$ for $3 \mathrm{~d}$. The culture supernatant was measured daily for chitosanase activity.

\subsection{Purification of Chitosanase}

Protein precipitation was performed by adding $480 \mathrm{~g}$ of $\left(\mathrm{NH}_{4}\right)_{2} \mathrm{SO}_{4}$ to $600 \mathrm{~mL}$ of culture supernatant. The solution was kept at $4{ }^{\circ} \mathrm{C}$ overnight. The precipitate was centrifuged at 12,000 $\mathrm{x} \mathrm{g}$ for $30 \mathrm{~min}$ and then dissolved in $50 \mathrm{~mL}$ of $20 \mathrm{mM}$ Tris-HCl buffer ( $\mathrm{pH}$ 7) to produce the crude enzyme solution. The enzyme solution was then loaded onto a Macro-Prep High $S$ column, which had been equilibrated with $20 \mathrm{mM}$ Tris- $\mathrm{HCl}$ buffer, and eluted by a linear gradient of $0-1 \mathrm{M} \mathrm{NaCl}$ in the same buffer. The obtained fraction, which showed the chitosanase, was then further purified by HPLC analysis using the KW802.5 column following the conditions: mobile phase, $0.3 \mathrm{M} \mathrm{NaCl}$ in $20 \mathrm{mM}$ Tris- $\mathrm{HCl}$ buffer ( $\mathrm{pH}$ 7); injection volume, $20 \mu \mathrm{L}$; temperature, $20^{\circ} \mathrm{C}$; flowrate, $1 \mathrm{~mL} / \mathrm{min}$; and detector, ultraviolet $230 \mathrm{~nm}$. The MW of the purified chitosanase was determined using the SDS-PAGE method.

\subsection{Effects of $\mathrm{pH}$ and Temperature on Activity and Stability of Chitosanase}

The optimal temperature for the reaction of TKU032 chitosanase was determined over a range of $4-100{ }^{\circ} \mathrm{C}$ with $30 \mathrm{~min}$ incubation. Thermal stability was determined by treating the enzyme at a range of temperatures for $30 \mathrm{~min}$. The residual activity of the treated enzyme was measured under the standard conditions of the chitosanase activity assay.

The effect of $\mathrm{pH}$ on TKU32 chitosanase activity was investigated using the buffer systems, including glycine- $\mathrm{HCl}$, acetate, sodium phosphate, and $\mathrm{Na}_{2} \mathrm{CO}_{3}-\mathrm{NaHCO}_{3}$. The optimal $\mathrm{pH}$ of TKU032 chitosanase was tested using a range of 2 to 11 . To investigate the $\mathrm{pH}$ stability of TKU032 chitosanase, the enzyme was pre-treated from $\mathrm{pH} 2$ to 11 for $30 \mathrm{~min}$; its residual activity was measured at $\mathrm{pH}$, as described above.

\subsection{Effect of Metal Ions on Chitosanase Activity}

TKU032 chitosanase was pre-incubated for $30 \mathrm{~min}$ at $37^{\circ} \mathrm{C}$ with various metal ion salts and an enzyme inhibitor (5 mM), including: $\mathrm{Cu}^{2+}, \mathrm{Zn}^{2+}, \mathrm{Mg}^{2+}, \mathrm{Na}^{+}, \mathrm{Ba}^{2+}, \mathrm{Ca}^{2+}, \mathrm{Fe}^{2+}$, and EDTA. The residual chitosanase activity was then measured, using the methods described above. 


\subsection{Substrate Specificity of Chitosanase}

TKU032 chitosanase was incubated in $20 \mathrm{mM}$ Tris- $\mathrm{HCl}$ buffer with numerous substrates at $70{ }^{\circ} \mathrm{C}$ for $30 \mathrm{~min}$. These included: dextran, potato starch, cellulose powder, $\alpha$-chitin powder, $\beta$-chitin powder, chitosan powder, colloidal chitin, colloidal chitosan, and $p$ NPG. The enzyme activity in water-soluble chitosan was used as a control.

\subsection{Antioxidant Activity Assay}

DPPH radical scavenging activity was tested as per the previous methods, with modifications [51]. Briefly, $20 \mu \mathrm{L}$ of sample was mixed with $980 \mu \mathrm{L}$ DPPH-methanol solution and the mixture was kept in the dark for $20 \mathrm{~min}$. The solution was then measured for optical density at $517 \mathrm{~nm}$. The antioxidant activity was calculated using formula (1):

$$
\text { DPPH radical scavenging activity }(\%)=\left(\mathrm{A}_{1}-\mathrm{A}_{2}\right) / \mathrm{A}_{1} \times 100
$$

where A is the optical density of a blank sample and B is the optical density of the sample solution.

\section{9. aGI Activity Assay}

The aGI activity test followed the previously described methods [18]. In brief, $10 \mu \mathrm{L}$ of sample was mixed with an equal amount of yeast $\alpha$-glucosidase solution $(1 \mathrm{U})$ and $100 \mu \mathrm{L}$ phosphate buffer (100 mM, pH 6.8). The mixture was immediately incubated at $37^{\circ} \mathrm{C}$ for $30 \mathrm{~min}$. The reaction of the enzyme and substrate was started by adding $10 \mu \mathrm{L} p$-nitrophenyl glucopyranoside to the mixture, and then incubating at $37{ }^{\circ} \mathrm{C}$ for a further $30 \mathrm{~min}$. $130 \mu \mathrm{L} \mathrm{Na} \mathrm{CO}_{3}$ solution $(1 \mathrm{M})$ was added to the mixture to stop the reaction. The final solution was measured at $410 \mathrm{~nm}$. The aGI activity was calculated using the following formula (2):

$$
\text { aGI activity }(\%)=\left(B_{1}-B_{2}\right) / B_{1} \times 100
$$

where $B_{1}$ is the optical density of the blank sample, and $B_{2}$ is the optical density of the sample solution.

\section{Conclusions}

Chitosan oligosaccharides with various degrees of polymerization and biological activities could be efficiently produced using chitosanase to hydrolyze chitosan. In the current study, P. mucilaginosus TKU032 achieved the highest chitosanase production using shrimp head powder, an inexpensive material, as the sole $\mathrm{C} / \mathrm{N}$ source. The P. mucilaginosus TKU032 chitosanase was purified and unlike other Paenibacillus strains, had a MW of $59 \mathrm{kDa}$ and a high optimal temperature $\left(70{ }^{\circ} \mathrm{C}\right)$. In order to evaluate the bioactivity of COS, the oligomers obtained by hydrolyzing colloidal chitosan with TKU032 chitosanase were fractionalized and tested for aGI and antioxidant activities. The COS fraction with the highest MW (fraction I) demonstrated aGI activity, whereas the COS fractions with lower MW (fractions II and III) showed antioxidant activity. For the first time, the inhibitory mechanism of COS on yeast $\alpha$-glucosidase was investigated; the results suggest that it follows the mixed noncompetitive inhibition model. As such, chitosanase from P. mucilaginosus TKU032 may have potential applications in bioactive COS production for the food and pharmaceutical industries.

Author Contributions: Conceptualization, S.-L.W. and C.T.D.; Methodology, C.T.D. and T.N.T.; Software, C.T.D.; Validation, S.-L.W. and C.T.D.; Formal Analysis, C.T.D., T.N.T., V.B.N., and A.D.N.; Investigation, C.T.D., T.N.T.; Resources, S.-L.W.; Data Curation, C.T.D.; Writing-Original Draft Preparation, S.-L.W and C.T.D.; Writing, Review \& Editing, S.-L.W. and C.T.D.; Visualization, S.-L.W. and C.T.D.; Supervision, S.-L.W.; Project Administration, S.-L.W.; Funding Acquisition, S.-L.W.

Funding: This work was supported in part by a grant from the Ministry of Science and Technology, Taiwan (MOST 106-2320-B-032-001-MY3).

Conflicts of Interest: The authors declare no conflict of interest. 


\section{References}

1. Zitouni, M.; Fortin, M.; Scheerle, R.K.; Letzel, T.; Matteau, D.; Rodrigue, S.; Brzezinski, R. Biochemical and molecular characterization of a thermostable chitosanase produced by the strain Paenibacillus sp. 1794 newly isolated from compost. Appl. Microbiol. Biotechnol. 2013, 97, 5801-5813. [CrossRef]

2. Kumar, M.N.V.R. A review of chitin and chitosan applications. React. Funct. Polym. 2000, 46, 1-27. [CrossRef]

3. Wang, S.L.; Liang, T.W. Microbial reclamation of squid pens and shrimp shells. Res. Chem. Interm. 2017, 43, 3445. [CrossRef]

4. Elieh-Ali-Komi, D.; Hamblin, M.R. Chitin and chitosan: Production and application of versatile biomedical nanomaterials. Int. J. Adv. Res. (Indore). 2016, 4, 411-427.

5. $\quad$ Liang, T.W.; Chen, W.T.; Lin, Z.H.; Kuo, Y.H.; Nguyen, A.D.; Pan, P.S.; Wang, S.L. An amphiprotic novel chitosanase from Bacillus mycoides and its application in the production of chitooligomers with their antioxidant and anti-inflammatory evaluation. Int. J. Mol. Sci. 2017, 17, 1302. [CrossRef]

6. Jo, S.H.; Ha, K.S.; Moon, K.S.; Kim, J.G.; Oh, C.G.; Kim, Y.C.; Apostolidis, E.; Kwon, Y.I. Molecular weight dependent glucose lowering effect of low molecular weight chitosan oligosaccharide (GO2KA1) on postprandial blood glucose level in SD rats model. Int. J. Mol. Sci. 2013, 14, 14214-14224. [CrossRef] [PubMed]

7. Lee, H.W.; Park, Y.S.; Choi, J.W.; Yi, S.Y.; Shin, W.S. Antidiabetic effects of chitosan oligosaccharides in neonatal streptozotocin-induced noninsulin-dependent diabetes mellitus in rats. Biol. Pharm. Bull. 2003, 26, 1100-1103. [CrossRef]

8. Tran, T.N.; Doan, C.T.; Nguyen, V.B.; Nguyen, A.D.; Wang, S.L. The isolation of chitinase from Streptomyces thermocarboxydus and its application in the preparation of chitin oligomers. Res. Chem. Interm. 2019, 45, 727-742. [CrossRef]

9. Doan, C.T.; Tran, T.N.; Nguyen, V.B.; Nguyen, A.D.; Wang, S.L. Reclamation of marine chitinous materials for chitosanase production via microbial conversion by Paenibacillus macerans. Mar. Drugs. 2018, 16, 429. [CrossRef]

10. Azuma, K.; Osaki, T.; Minami, S.; Okamoto, Y. Anticancer and anti-inflammatory properties of chitin and chitosan oligosaccharides. J. Funct. Biomater. 2015, 6, 33-49. [CrossRef]

11. Liang, T.W.; Chen, Y.J.; Yen, Y.H.; Wang, S.L. The antitumor activity of the hydrolysates of chitinous materials hydrolyzed by crude enzyme from Bacillus amyloliquefaciens V656. Process Biochem. 2007, 42, 527-534. [CrossRef]

12. No, H.K.; Park, N.Y.; Lee, S.H.; Meyers, S.P. Antibacterial activity of chitosans and chitosan oligomers with different molecular weights. Int. J. Food Microbiol. 2002, 74, 65-72. [CrossRef]

13. Sun, T.; Qin, Y.; Xu, H.; Xie, J.; Hu, D.; Xue, B.; Hua, X. Antibacterial activities and preservative effect of chitosan oligosaccharide Maillard reaction products on Penaeus vannamei. Int. J. Biol. Macromol. 2017, 105, 764-768. [CrossRef]

14. Wang, S.L.; Liu, C.P.; Liang, T.W. Fermented and enzymatic production of chitin/chitosan oligosaccharides by extracellular chitinases from Bacillus cereus TKU027. Carbohydr. Polym. 2012, 90, 1305-1313. [CrossRef]

15. Liang, T.W.; Liu, C.P.; Wu, C.; Wang, S.L. Applied development of crude enzyme from Bacillus cereus in prebiotics and microbial community changes in soil. Carbohydr. Polym. 2013, 92, 2141-2148. [CrossRef]

16. Nguyen, A.D.; Huang, C.C.; Liang, T.W.; Nguyen, V.B.; Pan, P.S.; Wang, S.L. Production and purification of a fungal chitosanase and chitooligomers from Penicillium janthinellum D4 and discovery of the enzyme activators. Carbohydr. Polym. 2014, 108, 331-337. [CrossRef]

17. Park, J.K.; Shimono, K.; Ochiai, N.; Shigeru, K.; Kurita, M.; Ohta, Y.; Tanaka, K.; Matsuda, H.; Kawamukai, M. Purification, characterization, and gene analysis of a chitosanase (ChoA) from Matsuebacter chitosanotabidus 3001. J. Bacteriol. 1999, 181, 6642-6649.

18. Doan, C.T.; Tran, T.N.; Nguyen, V.B.; Nguyen, A.D.; Wang, S.L. Conversion of squid pens to chitosanases and proteases via Paenibacillus sp. TKU042. Mar. Drugs 2018, 16, 83. [CrossRef]

19. Wang, S.L.; Yu, H.T.; Tsai, M.H.; Doan, C.T.; Nguyen, V.B.; Do, V.C.; Nguyen, A.D. Conversion of squid pens to chitosanases and dye adsorbents via Bacillus cereus. Res. Chem. Interm. 2018, 44, 4903-4911. [CrossRef]

20. Wang, C.L.; Su, J.W.; Liang, T.W.; Nguyen, A.D.; Wang, S.L. Production, purification and characterization of a chitosanase from Bacillus cereus. Res. Chem. Interm. 2014, 40, 2237-2248. [CrossRef] 
21. Liang, T.W.; Chen, Y.Y.; Pan, P.S.; Wang, S.L. Purification of chitinase/chitosanase from Bacillus cereus and discovery of an enzyme inhibitor. Int. J. Biol. Macromol. 2014, 63, 8-14. [CrossRef]

22. Liang, T.W.; Hsieh, J.L.; Wang, S.L. Production and purification of a protease, a chitosanase and chitin oligosaccharides by Bacillus cereus TKU022 fermentation. Carbohyd. Res. 2012, 362, 38-46. [CrossRef]

23. Wang, S.L.; Chen, T.R.; Liang, T.W.; Wu, P.C. Conversion and degradation of shellfish wastes by Bacillus cereus TKU018 fermentation for the production of chitosanase and bioactive materials. Biochem. Eng. J. 2009, 48, 111-117. [CrossRef]

24. Liang, T.W.; Kuo, Y.H.; Wu, P.C.; Wang, C.L.; Nguyen, A.D.; Wang, S.L. Purification and characterization of a chitosanase and a protease by conversion of shrimp shell wastes fermented by Serratia marcescens subsp. sakuensis TKU019. J. Chin. Chem. Soc-Taip. 2010, 57, 857-863. [CrossRef]

25. Boucher, I.; Dupuy, A.; Vidal, P.; Neugebauer, W.A.; Brzezinski, R. Purification and characterization of a chitosanase from Streptomyces N174. Appl. Microbiol. Biotechnol. 1992, 38, 188-193. [CrossRef]

26. Liang, T.W.; Lo, B.C.; Wang, S.L. Chitinolytic bacteria-assisted conversion of squid pen and its effect on dyes and adsorption. Mar. Drugs 2015, 13, 4576-4593. [CrossRef]

27. Wang, S.L.; Wu, P.C.; Liang, T.W. Utilization of squid pen for the efficient production of chitosanase and antioxidants through prolonged autoclave treatment. Carbohydr. Res. 2009, 244, 979-984. [CrossRef]

28. Wang, S.L.; Chen, S.J.; Liang, T.W.; Lin, Y.D. A novel nattokinase produced by Pseudomonas sp. TKU015 using shrimp shells as substrate. Process Biochem. 2009, 44, 70-76. [CrossRef]

29. Wang, S.L.; Su, Y.C.; Nguyen, V.B.; Nguyen, A.D. Reclamation of shrimp heads for the production of $\alpha$-glucosidase inhibitors by Staphylococcus sp. TKU043. Res. Chem. Intermed. 2018, 44, 4929-4937. [CrossRef]

30. Wang, S.L.; Wu, Y.Y.; Liang, T.W. Purification and biochemical characterization of a nattokinase by conversion of shrimp shell with Bacillus subtilis TKU007. New Biotechnol. 2011, 28, 196-202. [CrossRef]

31. Doan, C.T.; Tran, T.N.; Nguyen, M.T.; Nguyen, V.B.; Nguyen, A.D.; Wang, S.L. Anti- $\alpha$-glucosidase activity by a protease from Bacillus licheniformis. Molecules 2019, 24, 691. [CrossRef]

32. Nguyen, V.B.; Wang, S.L. New novel $\alpha$-glucosidase inhibitors produced by microbial conversion. Process Biochem. 2018, 65, 228-232. [CrossRef]

33. Nguyen, V.B.; Nguyen, T.H.; Doan, C.T.; Tran, T.N.; Nguyen, A.D.; Kuo, Y.H.; Wang, S.L. Production and bioactivity-guided isolation of antioxidants with $\alpha$-glucosidase inhibitory and anti-NO properties from marine chitinous material. Molecules 2018, 23, 1124. [CrossRef]

34. Nguyen, V.B.; Wang, S.L. Production of potent antidiabetic compounds from shrimp head powder via Paenibacillus conversion. Process Biochem. 2019, 76, 18-24. [CrossRef]

35. Nguyen, V.B.; Nguyen, A.D.; Wang, S.L. Utilization of fishery processing byproduct squid pens for Paenibacillus sp. fermentation on producing potent $\alpha$-glucosidase inhibitors. Mar. Drugs. 2017, 15, 274. [CrossRef]

36. Nguyen, V.B.; Wang, S.L. Reclamation of marine chitinous materials for the production of $\alpha$-glucosidase inhibitors via microbial conversion. Mar. Drugs. 2017, 15, 350. [CrossRef]

37. Liang, T.W.; Tseng, S.C.; Wang, S.L. Production and characterization of antioxidant properties of exopolysaccharides from Paenibacillus mucilaginosus TKU032. Mar. Drugs. 2016, 12, 40. [CrossRef]

38. Liang, T.W.; Wu, C.C.; Cheng, W.T.; Chen, Y.C.; Wang, C.L.; Wang, I.L.; Wang, S.L. Exopolysaccharides and antimicrobial biosurfactants produced by Paenibacillus macerans TKU029. Appl. Biochem. Biotech. 2014, 172, 933-950. [CrossRef]

39. Doan, C.T.; Tran, T.N.; Nguyen, V.B.; Vo, T.P.K.; Nguyen, A.D.; Wang, S.L. Chitin extraction from shrimp waste by liquid fermentation using an alkaline protease-producing strain, Brevibacillus parabrevis. Int. J. Biol. Macromol. 2019, 131, 706-715. [CrossRef]

40. Garcia-Gonzalez, E.; Poppinga, L.; Fünfhaus, A.; Hertlein, G.; Hedtke, K.; Jakubowska, A.; Genersch, E. Paenibacillus larvae chitin-degrading protein PlCBP49 is a key virulence factor in American foulbrood of honey bees. PLoS Pathogen. 2014, 10, e1004284. [CrossRef]

41. Singh, A.K.; Chhatpar, H.S. Purification and characterization of chitinase from Paenibacillus sp. D1. Appl. Biochem. Biotechnol. 2011, 164, 77-88. [CrossRef]

42. Kim, Y.H.; Park, S.K.; Hur, J.Y.; Kim, Y.C. Purification and characterization of a major extracellular chitinase from a biocontrol bacterium, Paenibacillus elgii HOA73. Plant Pathol. J. 2017, 33, 318-328. [CrossRef]

43. Loni, P.P.; Patil, J.U.; Phugare, S.S.; Bajekal, S.S. Purification and characterization of alkaline chitinase from Paenibacillus pasadenensis NCIM 5434. J. Basic Microbiol. 2014, 54, 1080-1089. [CrossRef] 
44. Ueda, J.; Kurosawa, N. Characterization of an extracellular thermophilic chitinase from Paenibacillus thermoaerophilus strain TC22-2b isolated from compost. World J. Microbiol. Biotechnol. 2015, 31, 135-143. [CrossRef]

45. Jung, W.J.; Kuk, J.K.; Kim, K.Y.; Kim, T.H.; Park, R.D. Purification and characterization of chitinase from Paenibacillus illinoisensis KJA-424. J. Microbiol. Biotechnol. 2005, 15, 274-280.

46. Fu, X.; Yan, Q.; Wang, J.; Yang, S.; Jiang, Z. Purification and biochemical characterization of novel acidic chitinase from Paenibacillus barengoltzii. Int. J. Biol. Macromol. 2016, 91, 973-979. [CrossRef]

47. Guo, X.; Xu, P.; Zong, M.; Lou, W. Purification and characterization of alkaline chitinase from Paenibacillus pasadenensis CS0611. Chin. J. Catalys. 2017, 38, 665-672. [CrossRef]

48. Kimoto, H.; Kusaoke, H.; Yamamoto, I.; Fujii, Y.; Onodera, T.; Taketo, A. Biochemical and genetic properties of Paenibacillus glycosyl hydrolase having chitosanase activity and discoidin domain. J. Biol. Chem. 2002, 277, 14695-14702. [CrossRef]

49. Itoh, T.; Sugimoto, I.; Hibi, T.; Suzuki, F.; Matsuo, K.; Fujii, Y.; Taketo, A.; Kimoto, H. Overexpression, purification, and characterization of Paenibacillus cell surface expressed chitinase ChiW with two catalytic domains. Biosci. Biotechnol. Biochem. 2014, 78, 624-634. [CrossRef]

50. Meena, S.; Gothwal, R.K.; Saxena, J.; Nehra, S.; Mohan, M.K.; Ghosh, P. Effect of metal ions and chemical compounds on chitinase produced by a newly isolated thermotolerant Paenibacillus sp. BISR-047 and its shelf-life. Int. J. Curr. Microbiol. Appl. Sci. 2015, 4, 872-881.

51. Nguyen, V.B.; Wang, S.L.; Nguyen, A.D.; Lin, Z.H.; Doan, C.T.; Tran, T.N.; Huang, H.T.; Kuo, Y.H. Bioactivity-Gùded purification of novel herbal antioxidant and anti-NO compounds from Euonymus laxiflorus Champ. Molecules 2019, 24, 120. [CrossRef]

52. Naveed, M.; Phil, L.; Sohail, M.; Hasnat, M.; Baig, M.M.F.A.; Ihsan, A.U.; Shumzaid, M.; Kakar, M.U.; Khan, T.M.; Akabar, M.D.; Hussain, M.I.; Zhou, Q.G. Chitosan oligosaccharide (COS): An overview. Int. J. Biol. Macromol. 2019, 129, 827-843. [CrossRef]

(C) 2019 by the authors. Licensee MDPI, Basel, Switzerland. This article is an open access article distributed under the terms and conditions of the Creative Commons Attribution (CC BY) license (http:/ / creativecommons.org/licenses/by/4.0/). 